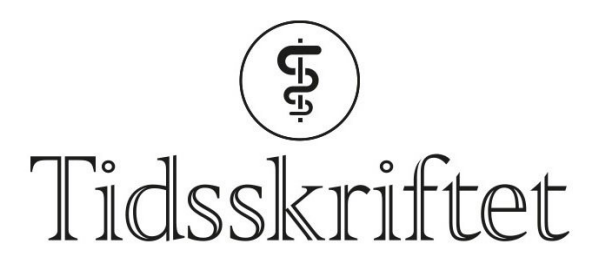

DEN NORSKE LEGEFORENING

\title{
«Hele Felleskatalogen» i behandling av rusmiddellidelser
}

KRONIKK

\section{J $\varnothing R G M \varnothing R L A N D$}

Jørg Mørland er spesialist i klinisk farmakologi, professor emeritus ved Senter for rus- og avhengighetsforskning, Universitetet i Oslo, og fagdirektør i Område for helsedata og digitalisering, Folkehelseinstituttet.

Forfatter har fylt ut ICMJE-skjemaet og oppgir ingen interessekonflikter.

\section{HELGE WAAL}

E-post: helge.waal@medisin.uio.no

Helge Waal er spesialist i psykiatri, professor emeritus ved Senter for rus- og avhengighetsforskning, Universitetet i Oslo, og faglig rådgiver ved Nasjonal kompetansetjeneste for tverrfaglig spesialisert behandling av ruslidelser (TSB), Oslo universitetssykehus.

Forfatter har fylt ut ICMJE-skjemaet og oppgir ingen interessekonflikter.

I Norge har forskrivningen av vanedannende medisiner vært restriktiv. Flere utviklingstrekk peker i liberaliserende retning. Samtidig vokser problemene med forskrivning av slike medisiner i mange land - inkludert Norge.

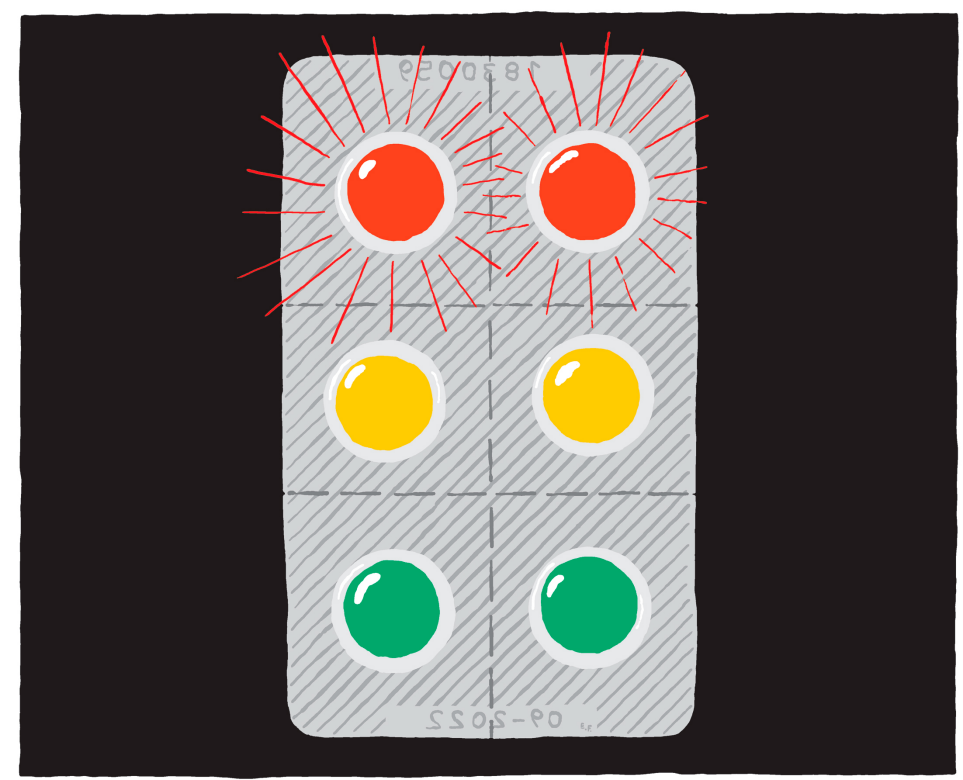

Illustrasjon (C Espen Friberg

De norske retningslinjene for forskrivningen av vanedannende legemidler har tradisjonelt vært strenge. Sedativer og hypnotika skal som hovedregel bare forskrives i korte perioder i tilknytning til påvisbare påkjenninger. Sterke analgetika skal med unntak for terminale 
lidelser bare forskrives tidsavgrenset ved skader og postoperative og akutte smertetilstander, mens det skal utvises forsiktighet ved kroniske lidelser. Ved ruslidelser skal man være spesielt tilbakeholdne med rusmulige midler $(1,2)$. I slike tilfeller er hovedregelen at legen bestemmer medikamentvalg i samsvar med retningslinjer og veiledere, men selvsagt skal pasienten så langt som mulig ha innflytelse på valgene - her som ellers i helsevesenet.

\section{Rusmiddelpolitikk på gyngende grunn}

Vi opplever at denne politikken i dag blir utfordret. Helsevesenet og sosialtjenesten har hatt lovbestemt ansvar for behandling av ruslidelser i mange tiår. Etter at løsgjengerloven ble opphevet i 2006, har det ikke vært hjemmel for å gripe inn med straffereaksjoner for rusatferd. Det har lenge vært alminnelig enighet om at når rusmiddelbruk fører til sykelige tilstander, er det helse- og omsorgsvirksomhetene som har ansvaret. Rusavhengige skal behandles, ikke straffes. De sentrale spørsmålene er derfor ikke om rusmiddelbrukeren skal behandles, men når og hvordan. Noen signaler fra politisk hold og fagfeltet gir grunn til bekymring.

Et signal er at man fra politisk hold synes å ville bestemme hvordan legemiddelassistert rehabilitering (LAR) skal styres og utvikles. Den gjeldende regjeringsplattformen, Jeløyaerklæringen, sier at legemiddelassistert rehabilitering skal «inkludere flere legemidler og sørge for $ø \mathrm{kt}$ valgfrihet i LAR, samt gjennomføre fors $ø \mathrm{k}$ med heroinassistert behandling innenfor LAR» (3). Brukerne skal ha større innflytelse på medikamentvalgene. Det er ikke klart hva dette betyr, men de grunnleggende forutsetningene for legemiddelassistert rehabilitering er ikke nevnt. Det sentrale er at den avhengige skal kunne stabiliseres på et middel som virker så langsomt og så langvarig at han eller hun kan behandles med tilførsel av medikamentet en gang i døgnet. Målsettingen er at den avhengige skal kunne leve sitt liv i samfunnet uten å domineres av pendlingen mellom abstinens og ruspåvirkning.

Norge bruker i dag de to internasjonalt godkjente og anbefalte medikamentene metadon og buprenorfin. Et aktuelt alternativ er morfin med langsom frigivelse (slow release morphine), som er i bruk i Østerrike og noen andre land (4). Behandlingsresultater er likeverdige med metadon, og noen pasienter beskriver noe bedre livskvalitet (5). Preparatet er imidlertid vanskeligere å styre og vesentlig dyrere. Behandling med korttidsvirkende preparater som heroin (diacetylmorfin) forutsetter tilførsel 2-3 ganger hver dag og krever derfor opprettelse av sentre der pasienten må komme flere ganger daglig alle ukens dager på ubestemt tid (6). Legemiddelassistert rehabilitering pålegges i dag å redusere kostnadene, og det er ingen signaler om at nye medikamenter skal følges av flere ressurser.

Fra brukerhold har det kommet forventninger om at brukeren selv skal kunne velge medikament, også når det gjelder andre opioider, slik som morfinklorid og oksykodon. Om man har vanemessig bruk av heroin, vil noe av det man lengter etter være den umiddelbare rusvirkningen etter inntak. Dette ønsket, som forsterkes ved gjentatt bruk, er sentralt for forståelsen av en rusmiddellidelse (7). Ettertraktede midler har til felles at de har rask og intensiv virkning - ikke at de har langsom absorpsjon og gradvis overgang til hjernen, som f.eks. metadon. Det kan lett gi konflikter og misnøye mellom pasienter og leger dersom behandlingen utvikles med forventning om at brukerønsket og brukerens opplevelse av virkningen skal bli styrende.

Det er også grunn til å forvente vansker når det gjelder kontrolltiltak. I Danmark, hvor kontrollen er mindre, er antallet dødsfall knyttet til metadon høyere enn antallet dødsfall forårsaket av heroin (8). I England er antallet overdosedødsfall forårsaket av heroin lavere enn antallet forårsaket av opioidholdige legemidler. Her er metadon den sterkeste bidragsyteren (9). I Norge hadde vi en økende andel dødsfall knyttet til metadon frem til 2012 (10). Dette medførte større vekt på ulike former for kontroll av utlevering og bruk, og andelen «metadondødsfall» har sunket (10). Andelen knyttet til heroin er også betydelig redusert, men mortaliteten som følge av opioider er likevel relativt uendret på grunn av $ø$ kning av dødsfallene knyttet til andre opioider, deriblant medikamenter som etterspørres 
av brukere (10).

En bekymring her er at også enkelte leger har begynt å forskrive andre opioider, særlig morfinsulfat, men også oksykodon. Dette gjelder blant andre Bymisjonens lavterskeltiltak i Oslo sentrum, 24sju, der det er anbefalt at man skal «bruke hele Felleskatalogen» i arbeidet for å hjelpe de mest forkomne brukerne (11). Dette uttrykket, «bruke hele Felleskatalogen», har fått betydelig gjennomslag i mediene og er også brukt i politiske drøftinger. Men hva betyr det egentlig? Rusmiddelbrukerne skal, som alle andre, selvsagt få den medikamentelle hjelpen som er indisert etter hvilken lidelse de har. Samtidig må man ta hensyn til komplikasjonsfare og forsvarlighet. Uttrykket tolkes imidlertid ofte slik at rusavhengige i større grad skal kunne få behandling med det opioidet de selv ønsker ut fra egen opplevelse. Flere brukerorganisasjoner krever nå vedlikeholdsbehandling også for brukere av sentralstimulerende midler og benzodiazepiner. Behandlingen av alkoholavhengighet nevnes også i denne sammenhengen (12). På denne bakgrunnen er det ikke forbausende at vi i dag ser $\emptyset$ kning i forskrivning av vanedannende midler, spesielt opioider som oksykodon og tramadol $(12,13)$. Dødsfallsstatistikken viser at nettopp disse midlene i økende grad medvirker til overdosedødsfall (10).

\section{Benzodiazepiner til besvær}

Et annet aspekt er at mange brukere gjerne vil ha benzodiazepiner. Som vi i dag vet, er faren for avhengighetsutvikling betydelig. På tross av anbefalingene om at all behandling med benzodiazepiner skal være kortvarig, viser unders $\emptyset$ kelser i reseptregisteret at $7 \%$ av alle som brukte angstdempende medisiner og $15 \%$ av alle som brukte søvnmidler hadde et overforbruk av legemidlet, definert som mer enn 365 definerte døgndoser (14). Dette svarer til mer enn daglig bruk gjennom et helt år. En svensk undersøkelse viser at også forskrivning til barn og unge tenderer til å vare over tid og bli vanskelig å avslutte (15).

Ulempene ved langvarig forskrivning er betydelig, med $ø$ kt forekomst av fall, redusert kognisjon, funksjonsvansker og i realiteten også episodisk hukommelsessvikt. I tillegg er det vanskelig for disse brukerne å oppfylle kravene i førerkortforskriften. En assosiasjon til forekomst av Alzheimers sykdom er nylig påvist (16). Det er i dag ingen aksepterte indikasjoner for langtidsbehandling med disse preparatene for psykiske lidelser eller søvnvansker. Bruk gir umiddelbar lettelse for uro og anspenthet, mens langvarig bruk fører til problemer med stressintoleranse og svekket døgnregulering. Mange rusmiddelbrukere selvmedisinerer ulike diffuse vansker og $\emptyset$ nsker fortsatt forskrivning.

En stor norsk kunnskapsoppsummering viser entydig at det ikke er noen dokumentasjon for nytten av langtidsbruk for rusmiddelbrukere samtidig som bruk gir $ø$ kt forekomst av irritabilitet, dysfori og svekket impulskontroll (17). Den viser også at bruken av benzodiazepiner inngår i rusmiddeldynamikken slik at medikasjonen $\emptyset$ ker rusopplevelsen av andre rusmidler. De midlene som etterspørres, er de som har rask stigning av konsentrasjonen i blod og rask overgang til virkestedene i hjernen (GABA $A_{A}$-reseptorene)altså de som gir størst rusvirkning.

\section{«Er det så farlig, da?»}

Hvor farlig er egentlig dette? Det farmakodynamiske samvirket gir ikke bare forsterket rusopplevelse av for eksempel opioider. Den forsterker også dempingen av respirasjonen, og rettstoksikologiske undersøkelser viser at benzodiazepiner er involvert i mer enn to tredeler av opioiddominerte overdosedødsfall (18). De er også involvert i en betydelig del av voldskriminaliteten og ulike typer ulykker. Det er derfor god grunn til å begrense bruken så mye som mulig og til å ha en restriktiv forskrivning av benzodiazepiner til rusmiddelbrukere.

I USA og en del andre land har det vært en dramatisk økning i bruken av opioide legemidler. Først så man økningen for oksykodon, som ble lansert som ufarlig og lite avhengighetsskapende i en massiv lanseringskampanje av firmaet Purdue Pharma i slutten 
av 199o-årene. Dette ble fulgt av en dramatisk økning i overdosedødsfall, slik det er vist i en stor amerikansk vitenskapelig analyse av sammenhengen mellom forskrivning av opioider og overdosedødsfall (19).

Analyser av forskrivningsmønster og dødsfall viste dessuten at når opioider forskrives sammen med benzodiazepiner i smertebehandling, øker andelen som utvikler avhengighet dramatisk (19). Samtidig finner man at benzodiazepinene er involvert i mange av $\mathrm{d} ø \mathrm{~d}$ sfallene. Mortaliteten $\emptyset$ ker systematisk ved samtidig forskrivning av benzodiazepiner (20).

\section{Snillhet er ikke alltid snillhet}

Det er altså mange grunner til å forsvare den relativt strenge norske praksisen for forskrivning av vanedannende legemidler som opioidanalgetika, benzodiazepiner og benzodiazepinlignende sedativer og hypnotika. Leger i USA opplever ikke sjelden en sterk forventning om at pasientenes forskrivningsønsker skal imøtekommes - så lenge pasienten kan betale. Det er få virksomme restriksjoner og inntil nylig nokså liten samfunnsmessig støtte for slike reguleringer.

Også i Norge kan man merke økte krav om legemidler for å lindre ulike ubehagstilstander. Men uro, mistrivsel og smerte er alle fenomener som har viktige signalfunksjoner både i den enkeltes liv og i samfunnet. Norske leger har til nå arbeidet innenfor et regelverk og med anbefalinger som gir støtte til at forskrivninger skal knyttes til klare medisinske indikasjoner. Det er viktig at norske leger beholder slik støtte - både fra medisinske og politiske miljøer. Det er ikke dermed sagt at bruken av legemidler ikke kan utvides, men som ellers i medisinsk behandling må dette skje på bakgrunn av faglige kunnskapsoppsummeringer eller som ledd i godt planlagte kontrollerte kliniske fors $ø$ k.

\section{LITTERATUR:}

1. Norsk legemiddelhåndbok. https://legemiddelhandboka.no/(21.1.2019).

2. Vanedannende legemidler. Nasjonal faglig veileder vanedannende legemidler - rekvirering og forsvarlighet. Oslo: Helsedirektoratet, 2014.

https://helsedirektoratet.no/retningslinjer/vanedannende-legemidler (21.1.2019).

3. Regjeringen. Jeløya-plattformen.

https://www.regjeringen.no/no/dokumenter/politisk-plattform/id2585544/\#k9 (21.1.2019).

4. European Monitoring Centre for Drugs and Drug Addiction. Austria - Country Drug Report 2018. http://www.emcdda.europa.eu/countries/drug-reports/2018/austria_en (21.1.2019).

5. Ferri M, Minozzi S, Bo A et al. Slow-release oral morphine as maintenance therapy for opioid dependence. Cochrane Database Syst Rev 2013; 6: CDoog879. [PubMed]

6. Waal H, Ohldieck C, Clausen T. Heroinassistert behandling - Et svar på dagens utfordringer i Norge? Oslo/Bergen: Senter for senter for rus- og avhengighetsforskning, Nasjonal kompetansetjeneste TSB, Haukeland universitetssykehus, 2017.

7. Mørland J, Waal H. Rus og avhengighet. Oslo: Universitetsforlaget, 2016.

8. Narkotikasituationen i Danmark 2017 - Nationale data. København: Sundhedsstyrelsen, 2017. https://www.sst.dk/da/udgivelser/2017/narkotikasituationen-i-danmark-2017 (21.1.2019).

9. Reducing Opioid-Related Deaths in the UK. London: Advisory Council on the Misuse of Drugs, 2016. https://www.gov.uk/government/publications/reducing-opioid-related-deaths-in-the-uk (21.1.2019).

10. Amundsen E, Gjersing L. Narkotikautløste dødsfall i Norge i 2016. Folkehelseinstituttet. https://www.fhi.no/hn/statistikk/rusmiddelstatistikk/narkotikautloste-dodsfall-i-norge-i-2016/ (21.1.2019).

11. Johnsrud N. De narkomanes lege. Dagsavisen 14.4.2016.

https://www.dagsavisen.no/oslo/de-narkomanes-lege-1.711639 (21.1.2019). 
12. Skårderud JR. Vil gi narkotika til flere. Klassekampen 17.8.2018.

https://dagens.klassekampen.no/2018-o8-17/vil-gi-narkotika-til-flere (21.1.2019).

13. Sakshaug S, Strøm H, Berg C et al. Legemiddelforbruket i Norge 2013-2017. Oslo:

Folkehelseinstituttet, 2018:1890-9647.

https://www.fhi.no/publ/2018/legemiddelforbruket-i-norge-20132017/ (21.1.2019).

14. Rossow I, Bramness JG. The total sale of prescription drugs with an abuse potential predicts the number of excessive users: a national prescription database study. BMC Public Health 2015; 15: 288. [PubMed][CrossRef]

15. Sidorchuk A, Isomura K, Molero Y et al. Benzodiazepine prescribing for children, adolescents, and young adults from 2006 through 2013: A total population register-linkage study. PLoS Med 2018; 15: e1002635. [PubMed][CrossRef]

16. Tapiainen V, Taipale H, Tanskanen A et al. The risk of Alzheimer's disease associated with benzodiazepines and related drugs: a nested case-control study. Acta Psychiatr Scand 2018; 138: 91-10o. [PubMed][CrossRef]

17. Nilsen EM, Bjørner T, Høiseth G et al. Benzodiazepiner i behandling av personer med rusmiddelproblemer. Rapport nr 6-2007. Oslo: Nasjonalt kunnskapssenter for helsetjenesten, 2007.

18. Karinen R, Konstantinova-Larsen S, Normann PT et al. Heroin deaths in Norway in 2000 and 2009: A comparative study of polydrug use. Heroin Addict Relat Clin Probl 2018; 20: 23-30.

19. National Academies of Sciences, Engineering, and Medicine. Pain Management and the Opioid Epidemic: Balancing Societal and Individual Benefits and Risks of Prescription Opioid Use. Washington, DC: The National Academies Press, 2017.

20. Park TW, Saitz R, Ganoczy D et al. Benzodiazepine prescribing patterns and deaths from drug overdose among US veterans receiving opioid analgesics: case-cohort study. BMJ 2015; 350: h2698. [PubMed][CrossRef]

Publisert: 11. februar 2019. Tidsskr Nor Legeforen. DOI: 10.4045/tidsskr.18.0678

Mottatt 30.8.2018, første revisjon innsendt 22.10.2018, godkjent 5.11.2018.

(C) Tidsskrift for Den norske legeforening 2020. Lastet ned fra tidsskriftet.no 